DEPÓSITO LEGAL ZU2020000153

Esta publicación científica en formato digital

es continuidad de la revista impresa

ISSN 0041-8811

E-ISSN 2665-0428

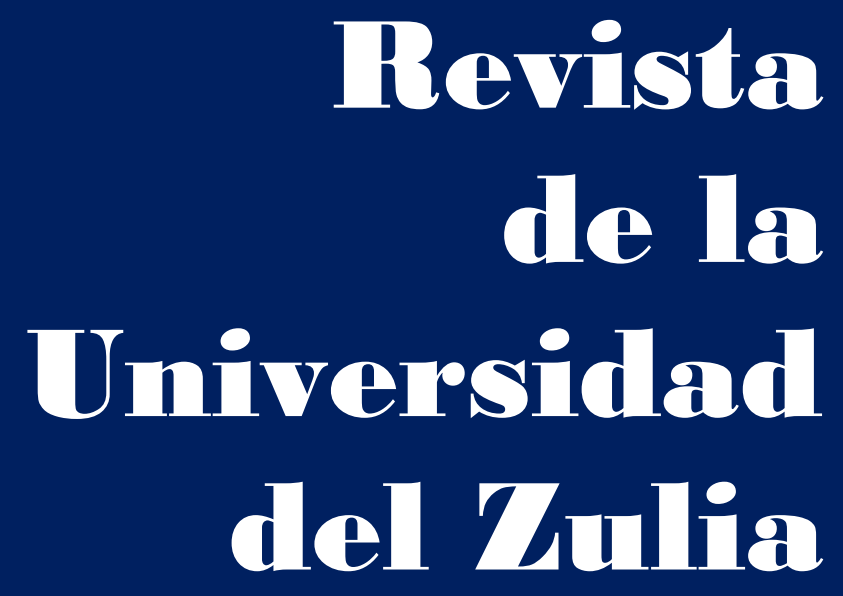

Fundada en 1947

por el Dr. Jesús Emrique Lossada

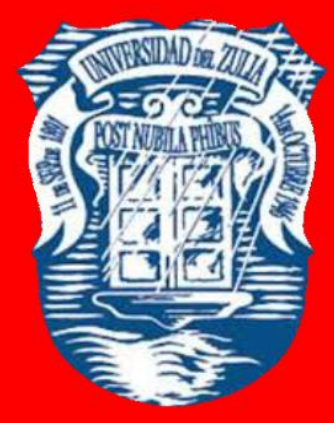

Ciencias

Sociales

y Arte

Año $12 \quad N^{\circ} 34$

Septiembre - Diciembre 2021

Tercera Época

Maracaibo-Veneruela 


\title{
Nociones sobre la Familia y el Buen Vivir Ecuatoriano
}

\author{
Jorge Isaac Calle García * \\ Jorge Isaac Calle Antón **
}

RESUMEN

La investigación tiene como objetivo establecer algunas nociones sobre la Familia y el Buen Vivir ecuatoriano; se aborda con la estrategia de investigación descriptiva-documental, con un enfoque en el método analítico. La importancia recae en el vínculo entre ambas instituciones, toda vez que al asumir al Buen Vivir como un conjunto de derechos a satisfacer respetando a la naturaleza, la Familia representa la primera estructura de responsabilidades y derechos de las personas y, al cumplir con ellas, igualmente se hace desde la consideración al entorno natural. Además, el Buen Vivir implica colocar como eje central la igualdad, tal como sucede con la Familia. En la conclusión más relevante, se sostiene, que la República del Ecuador le otorga supremacía constitucional a la Familia y al Buen Vivir pues, en conjunto, incorporan derechos, perspectivas y concepciones ancestrales adaptados al presente, con esquemas y contenidos que permiten el desarrollo.

PALABRAS CLAVE: Familia; política y bienestar social; sociedad multiétnica; Constitución; Ecuador.

* Docente Facultad de Derecho. Universidad Laica Eloy Alfaro de Manabí, Ecuador. ORCID: https://orcid.org/0000-0001-6567-2762. E-mail: jcallegarcia@yahoo.es.

** Estudiante de la Universidad Laica Eloy Alfaro de Manabí, Ecuador. ORCID: https://orcid.org/0000-0002-3745-1038. E-mail: calleanton@gmail.com.

Recibido: 09/06/2021

Aceptado: 02/08/2021 


\section{Notions about the Family and Ecuadorian Good Living}

ABSTRACT

The research aims to establish some notions about the Family and The Ecuadorian Good Living, it is addressed with the descriptive-documentary research strategy, with a focus on the analytical method. The importance lies in the link between both institutions, since by assuming Good Living as a set of rights to be satisfied respecting nature, the Family represents the first structure of responsibilities and rights of people and, in complying with them, it is also done from the consideration of the natural environment. In addition, Good Living implies placing equality as the central axis, as is the case with the Family. In the most relevant conclusion, it is maintained that the Republic of Ecuador grants constitutional supremacy to the Family and Good Living because, together, they incorporate ancestral rights, perspectives and conceptions adapted to the present, with schemes and contents that allow development.

KEY WORDS: Family; social policy and welfare; multiethnic societies; Constitutions; Ecuador.

Introducción

Las normas constitucionales les otorgan a sus contenidos realce, es decir, que cada acepción jurídica dispuesta con rango constitucional debe ser interpretada con jerarquía por encima de otras disposiciones. En el caso de la Constitución de la República del Ecuador (2008) estatuye dos instituciones o figuras de indudable relevancia para el desarrollo del entorno: el Sumak Kawsay o Buen Vivir y la Familia, ambos están vinculados a la naturaleza, pues el primero de ellos procura su respeto con una perspectiva biocéntrica; en tanto que el segundo, es el soporte natural de las personas y requiere de los elementos que otorga la naturaleza para la sobrevivencia de cada uno de sus miembros, no con una visión antropocéntrica sino del conjunto de las personas; combinarlos trae consigo un camino que debe llevar al desarrollo.

En este sentido, la Declaración de los Derechos Humanos (1948) ha establecido la institución Familia y, de ahí el ordenamiento jurídico de la República del Ecuador lo ha enfatizado; además, el Buen Vivir se encuentra contemplado en diferentes disposiciones 
constitucionales ecuatorianas como reflejo de la importancia de los saberes, culturas y concepciones ancestrales nacidas en los grupos amerindios y que se han trasladado a los espacios urbanos, unificando la necesidad del respeto a la naturaleza como trayecto necesario para alcanzar el Buen Vivir en Familia.

Por ello, la presente investigación intenta establecer algunas nociones sobre la Familia y el Buen Vivir ecuatoriano. El esclarecimiento de las cuestiones esbozadas permite a las instituciones actuantes en lo referente al Derecho de Familia y al Derecho Constitucional, establecer mecanismos de desarrollo desde el núcleo familiar, pero desde la perspectiva ancestral que ordena el Sumak Kawsay.

Al tratarse de una investigación de carácter descriptivo-documental se basa en el método analítico. Sus fuentes para la recolección de información son: constitucional, legal, doctrinal y hemerográfico. La constitucional está referida a las normas derivadas de la Constitución de la República del Ecuador de 2008; la legal se presenta con el Código Civil (2005) y, en el ordenamiento jurídico en general; por su parte, la doctrinal se vincula con distintos criterios para desarrollar interpretaciones orientadas a alcanzar un entendimiento armónico del tema en cuestión; y, la hemerográfica se refiere a la revisión de periódicos, revistas, entre otros, con artículos y opiniones de interés al tema planteado.

Así, para lograr el referido objetivo, el presente manuscrito plantea tres aspectos, a saber: 1. Consideraciones conceptuales sobre la Familia y el Buen Vivir; 2. Responsabilidades de la Familia en la Constitución de la República del Ecuador; y, 3. Relaciones entre la Familia y el Buen Vivir como paradigma de vida; luego, se realizan unos comentarios finales a manera de conclusión.

\section{Consideraciones conceptuales sobre la Familia y el Buen Vivir}

Uno de los rasgos relevantes de la sociedad son los cambios que en ella se originan, principalmente desde la Familia, que se mantiene como el origen común, aunque cada una es diferente. La Familia es considerada la institución jurídica, sociológica, psicológica, biológica, más antigua y que traslada en un vínculo dialéctico entre sus miembros cada aprendizaje y 
esfuerzo, convirtiéndose en lazos estrechos que, de manera natural -por la cercanía emocional y/o física entre sus miembros- se mueve dentro de la misma.

La Familia repercute de manera significativa en los comportamientos de sus miembros, desde que se incorporan como miembros de la misma, ejerciendo distintos roles de acuerdo a la dinámica cultural en la que se desenvuelve el grupo completo, es el primer escenario en el que se conocen las necesidades humanas, tanto individuales como colectivas, $\mathrm{y}$, debe estructurarse bajo criterios de respeto, comprensión, solidaridad, libertad, entre otros. Al reunir, la familia, distintas personalidades que interactúan entre sí es menester que se establezcan parámetros de funcionamiento a lo interno de las mismas, así como también de la Familia con el resto de los grupos sociales, ello se lleva a cabo a través de instrumentos jurídicos tanto nacionales como internacionales.

En este sentido, el artículo 16 de la Declaración Universal de Derechos Humanos emanada de la Asamblea General de las Naciones Unidas (1948) establece que la Familia es el elemento natural de la sociedad, indicando lo siguiente:

"Artículo 16. 1. Los hombres y las mujeres, a partir de la edad núbil, tienen derecho, sin restricción alguna por motivos de raza, nacionalidad o religión, a casarse y fundar una familia, y disfrutarán de iguales derechos en cuanto al matrimonio, durante el matrimonio y en caso de disolución del matrimonio.

2. Sólo mediante libre y pleno consentimiento de los futuros esposos podrá contraerse el matrimonio.

3. La familia es el elemento natural y fundamental de la sociedad y tiene derecho a la protección de la sociedad y del Estado".

Aunado a lo anterior, diversas concepciones de Familia han sido elaboradas por la doctrina. En este sentido, desde una perspectiva sociológica, la Familia se define como un grupo caracterizado por una relación sexual suficientemente definida y permanente para promover a la procreación y educación de la prole; también se le conceptúa como a la agrupación relativamente permanente y socialmente autorizada de padres e hijos (Oliva Gómez y Villa Guardiola, 2014). Otra manera de definir a la Familia es desde la esfera jurídica, por virtud de la cual se hace énfasis en las obligaciones y derechos que tienen sus integrantes y que varían en función de la normativa de cada país. Por su parte, el concepto va ligado a la 
psicología si se tiene en cuenta la variable afectiva y la convivencia en un espacio específico (Salgar Cubillos, 2017).

Para esta investigación, la Familia ha sido entendida como soporte, base, núcleo, de la sociedad toda. Es el inicio de las relaciones interpersonales con respeto a la manera de pensar de cada miembro, pero los valores y principios en ella aprendidos deben permanecer como paradigma de vida, es decir que las experiencias ancestrales que han pasado de una generación a otra se renuevan para continuar en el presente, “...esto por cuanto una sociedad democrática caracterizada por el pluralismo, la tolerancia y el espíritu de apertura- supone el reconocimiento de una familia democrática y pluralista, y en consecuencia una reconsideración de la institución familiar desde esta nueva perspectiva" (Esborraz, 2015: 26).

Ahora bien, la renovación o relectura de la Familia deviene del reconocimiento de derechos que plantean, entre varios aspectos, la igualdad entre los miembros de la Familia, ya que se ha pasado de una Familia "tradicional" comprendida por padre, madre e hijos, a una Familia con distinta tipología o pluralidad de formas; de esta manera, en opinión de Esborraz (2015), se plantean los siguientes diversos modelos familiares, a saber:

- Familia matrimonial: que está constituida sobre la base del matrimonio y responde al denominado modelo familiar tradicional (identificado además con la heterosexualidad de los cónyuges) y se encuentra reconocida expresa o implícitamente por todos los textos constitucionales latinoamericanos vigentes.

- Familia convivencial: constituida mediante una unión convivencial, libre o de hecho, y tiene como condiciones necesarias la ausencia de impedimentos matrimoniales, la durabilidad, la singularidad y la estabilidad.

- $\quad$ Familia homoparental: constituida por una pareja formada por personas del mismo género y vinculadas entre sí mediante el matrimonio o una unión convivencial.

- $\quad$ Familia monoparental: se encuentra constituida por uno solo de los progenitores y sus descendientes, a la que se puede acceder de manera originaria mediante técnicas de reproducción asistida y/o la adopción por parte de personas solteras; o en forma derivada, como resultado de la extinción de una unión matrimonial o convivencial precedente, sin que el progenitor que se ha hecho cargo de los hijos haya vuelto a formar una nueva pareja. 
- Familia ensamblada: en este caso uno o ambos integrantes de la pareja aportan al nuevo núcleo familiar hijos de otras uniones precedentes sean éstas matrimoniales o convivenciales, o se suma otro progenitor a una familia monoparental originaria.

- Familia ampliada: se trata de una extensión de la familia originaria (compuesta por padres e hijos), se extiende también a los ascendientes e -incluso- a otros parientes o personas, básicamente nace de una obligación jurídica, pues al imponer a la familia (conjuntamente con el Estado y la sociedad) el cuidado de los ancianos, así como también de las personas adultas con capacidad diferente, se origina esta categoría de Familia.

- Familia indígena: por medio de ella se reconoce el derecho de los pueblos indígenas, especialmente los de América Latina o amerindios, a regirse por sus propias costumbres, tradiciones y organización social, siempre que las mismas sean compatibles con los derechos fundamentales previstos por el ordenamiento jurídico nacional y con los derechos humanos reconocidos internacionalmente.

Más allá de las diferentes tipologías de Familia, interesa resaltar que se mantienen compromisos de cuidado y protección entre sus miembros, enfatizando el hecho de las regulaciones para su funcionamiento.

En lo que respecta a los planteamientos normativos de la Familia en la República del Ecuador, es menester destacar el artículo 67 de la Constitución de la República del Ecuador (2008) que estatuye lo siguiente:

"Artículo 67. Se reconoce la familia en sus diversos tipos. El Estado la protegerá como núcleo fundamental de la sociedad y garantizará condiciones que favorezcan integralmente la consecución de sus fines. Estas se constituirán por vínculos jurídicos o de hecho y se basarán en la igualdad de derechos y oportunidades de sus integrantes.

El matrimonio es la unión entre hombre y mujer, se fundará en el libre consentimiento de las personas contrayentes y en la igualdad de sus derechos, obligaciones y capacidad legal".

De la disposición transcrita se refleja la aceptación amplísima que tiene el ordenamiento jurídico ecuatoriano acerca de la Familia, pues de manera enunciativa expresa diversos tipos de Familia sin encasillarlos, del mismo modo contempla la institución del matrimonio -entendido como punto de partida de las Familias tradicionales- entre un hombre y una mujer, pero 
reconoce sus mismos derechos y obligaciones familiares a aquellas Familias que se originan de las uniones estables o Familias convivenciales; de este modo el artículo 68 constitucional sostiene que:

“Artículo 68. La unión estable y monogámica entre dos personas libres de vínculo matrimonial que formen un hogar de hecho, por el lapso y bajo las condiciones y circunstancias que señale la ley, generará los mismos derechos y obligaciones que tienen las familias constituidas mediante matrimonio.

La adopción corresponderá sólo a parejas de distinto sexo".

De tal manera que, la Familia es contenido constitucional, y no solo en el caso ecuatoriano pues el constitucionalismo latinoamericano la ha asumido; ante ello Villabella Armengol (2016) sostiene la siguiente taxonomía: 1. Constituciones que no abordan el tema: Argentina, Chile; 2. Textos que realizan una regulación básica: Costa Rica, El Salvador, Honduras, México, Perú, Uruguay; 3. Cartas Magnas que efectúan una normativización extensiva: Brasil, Bolivia, Colombia, Ecuador, Guatemala, Nicaragua, Paraguay, Panamá y Venezuela.

Así, en la República del Ecuador la Familia -y sus miembros-, está vinculada con una amplísima gama de derechos consagrados en la Constitución Nacional de 2008, tales como: educación (artículo 26); movilidad humana (artículo 40); equiparación de oportunidades para las personas con discapacidad y atención psicológica gratuita (artículo 47); incentivo y apoyo productivo para los familiares de personas con discapacidad severa (artículo 48); cobertura de la Seguridad Social (artículo 49); vida, vida digna, integridad personal, igualdad, libre desarrollo de la personalidad, opinión y expresión, libertad de religión, orientación sexual, libertad reproductiva, reserva de convicciones, intimidad personal y familiar, inviolabilidad de domicilio, acceder a bienes y servicios públicos y privados de calidad, vivir en un ambiente sano, ecológicamente equilibrado, libre de contaminación y en armonía con la naturaleza, identidad personal y colectiva, entre otros (artículo 66).

Hechas las anteriores consideraciones en cuanto a la variable Familia, se pasa a establecer algunos comentarios conceptuales acerca del Buen Vivir o Sumak Kawsay contemplado desde el Preámbulo de la Constitución de la República del Ecuador de 2008, pero 
que tiene un origen mucho más ancestral, pues se trata de una terminología utilizada por los amerindios del Ecuador, cuyas connotaciones son múltiples. Desde la perspectiva del referido Preámbulo constitucional, aparece "Una nueva forma de convivencia ciudadana, en diversidad y armonía con la naturaleza, para alcanzar el buen vivir, el Sumak Kawsay". "De esta manera el Sumak Kawsay constituye un fin primordial del Estado, donde esta nueva concepción juega un papel trascendental en tanto promueve un desarrollo social y económico en armonía con la naturaleza" (Corte Constitucional de la República del Ecuador, 2015: Sentencia 166-15-SEPCC).

La Constitución de 2008 enarboló por vez primera el concepto y la filosofía del Buen Vivir como directriz fundamental del régimen instituido, y también como premisa de los individuos y las distintas colectividades a la hora de construir una sociedad mejor, entiéndase, plural, justa, incluyente, en armonía con la naturaleza. Esta novedosa cosmovisión de origen indígena cristalizó en un principio constitucional de cardinal importancia, el Buen Vivir o Sumak Kawsay, el cual trajo consigo el reconocimiento de una serie de derechos y garantías de índole social, económica, ambiental y política (Galiano Maritán y Tamayo Santana, 2018).

En este sentido, esta investigación asume el Buen Vivir como una meta o niveles de satisfacción a alcanzar, llegar o poseer, con respeto a la naturaleza. Aunado a ello, ha sido relacionado con los indígenas del continente americano a través de sus luchas y resistencia. "Se trata de un concepto nacido en el Abya Yala y todo lo que ha significado la lucha de los pueblos originarios contra la exclusión y el despojo que trajo consigo el colonialismo" (Ribadeneira Aroca, 2020: 42) y tiene trascendencia indígena y urbana, pues conecta ambos modos de vida con el respeto a la naturaleza, es decir que en el Sumak Kawsay coinciden diferentes modos de vida para proteger a la naturaleza, haciendo de su uso un factor de respeto, que ha surgido de postulados amerindios.

"El Sumak kawsay (vida límpida y armónica) en el caso de los kichwa de la Alta Amazonía ecuatoriana, orienta el modo de vivir. Norma las relaciones entre las personas en base a principios igualitarios, comunitarios y de reciprocidad; se alimenta del diálogo con la naturaleza y su dimensión espiritual" (Ortíz, 2009: 79). 
En este mismo orden de ideas, la satisfacción que trae aparejada el Sumak Kawsay sistematiza un cúmulo de derechos como vida, salud, familia, esparcimiento, pero que al ejercerlos se venere y considere a la naturaleza o Pacha Mama por su carácter vital y espiritual, en todo caso de incalculable valor. "El Sumak Kawsay se oficializa como política de Estado en el 2008, luego de haber sido considerado en la nueva Constitución del Ecuador" (Morocho Alija, 2017: 181).

"El sumak es la plenitud, lo sublime, excelente, magnífico, hermoso (a), superior. El kawsay es la vida, es ser estando: es dinámico, cambiante, no es una cuestión pasiva. Por lo Tanto, el Sumak Kawsay sería la vida en plenitud, la vida en excelencia material y espiritual" (Pérez Morón et. al., 2014: 55).

Aunado a lo anterior, constitucionalmente el Buen Vivir es asumido como un conjunto de derechos, pues el Título II Derechos, Capítulo Segundo Derechos del Buen Vivir, establece los siguientes: agua y alimentación, ambiente sano, comunicación e información, cultura y ciencia, educación, hábitat y vivienda, salud, trabajo y seguridad social; ello conectado con saberes, rutinas y horizontes en los que confluyen distintas formas de pensar, actuar, vivir y convivir, en especial con la naturaleza. Cardoso Ruíz et. al (2016) lo engloban como se indica a continuación:

“...el Buen vivir es vida en plenitud, saber vivir en armonía con los ciclos de la Madre Tierra, del Cosmos y de la existencia, entendiendo que todo está en equilibrio. El Buen vivir significa saber existir y cohabitar, que no hay vida más que en relación con todas las formas de vida animada e inanimada, ya que la humanidad misma es naturaleza. Como todo está en equilibrio, no se puede Vivir bien si los demás o alguien vive mal, o si para satisfacer necesidades vanas se deteriora o destruye la Madre Naturaleza".

De este modo, el artículo 3 constitucional en su numeral $5^{\circ}$ determina como deber primordial del Estado, “...planificar el desarrollo nacional, erradicar la pobreza, promover el desarrollo sustentable y la redistribución equitativa de los recursos y la riqueza, para acceder al buen vivir", de tal manera, que los planes, políticas, proyectos y programas de la administración gubernamental deben perfilarse hacia el Buen Vivir. De ello se desprende otro elemento más de la figura del Buen Vivir: el Estado y cada una de sus acciones, ya que ellas repercuten en la dinámica indígena y urbana, en conexión necesaria con la naturaleza. En este sentido, el 
artículo 83 de la Constitución de la República del Ecuador (2008), sostiene: "Artículo 83. Son deberes y responsabilidades de las ecuatorianas y los ecuatorianos, sin perjuicio de otros previstos en la Constitución y la ley: ...7. Promover el bien común y anteponer el interés general al interés particular, conforme al buen vivir"; en tal sentido, se expande el Buen Vivir, no solo como derechos sino también como deberes y responsabilidades.

Por lo anterior, se sostiene que el Buen Vivir comprende diferentes factores, de los cuales destaca la naturaleza, es decir que cada perspectiva que pueda englobar el mismo debe corresponderse con el respeto hacia la naturaleza por ser quien ostenta los recursos de la sobrevivencia del ser humano y su entorno, en este caso la Familia. Con el devenir de los tiempos se han configurado distintos mecanismos económicos, políticos, sociales, culturales, que utilizan recursos de la Pacha Mama para el desarrollo humano, en todo caso se debe hacer en aras de garantizar el Buen Vivir, tal como lo establece el artículo 275 de la Constitución de la República del Ecuador (2008):

"Artículo 275.- El régimen de desarrollo es el conjunto organizado, sostenible y dinámico de los sistemas económicos, políticos, socio-culturales y ambientales, que garantizan la realización del buen vivir, del sumak kawsay ... El buen vivir requerirá que las personas, comunidades, pueblos y nacionalidades gocen efectivamente de sus derechos, y ejerzan responsabilidades en el marco de la interculturalidad, del respeto a sus diversidades, y de la convivencia armónica con la naturaleza".

Como se evidencia del artículo anterior, el Buen Vivir no surge de la nada sino del esfuerzo mancomunado de personas, comunidades, pueblos, nacionalidades, con sus propios derechos y obligaciones, en aras de alcanzar las aspiraciones colectivas que permitan ejercer y disfrutar de los derechos que constitucionalmente engloba el Buen Vivir.

2. Responsabilidades de la Familia en la Constitución de la República del Ecuador

A la luz de la Constitución de la República del Ecuador (2008) la Familia tiene un cúmulo de responsabilidades que se plantean como derechos de algunos de sus miembros, lo cual implica que el resto tiene esas obligaciones; a su vez, el conjunto completo tiene obligaciones frente a personas o entes distintos a los que se encuentran dentro de la misma. "Es 
REVISTA DE LA UNIVERSIDAD DEL ZULIA. 3é época. Año $12 \mathrm{~N}^{\circ}$ 34, 2021

J. I. Calle García \& J. I. Calle Antón /// Nociones sobre la Familia y el Buen Vivir Ecuatoriano, 379-397

DOI: http://dx.doi.org/10.46925//rdluz.34.22

una unidad social, plural y compleja, no una simple reunión de unidades, de individualidades separadas o aisladas" (De La Fuente Linares, 2012: 62).

"Cada familia es única, como distintos son sus miembros, con diferentes modos de pensar y de sentir, sin embargo, algunas de las problemáticas más comunes por las que atraviesa el grupo en términos generales, tienen que ver con el fortalecimiento de la capacidad de la familia para atender sus propias necesidades, el equilibrio entre el trabajo y las responsabilidades familiares; la reducción de la violencia doméstica y el alivio de la pobreza" (Oliva Gómez; Villa Guardiola, 2013: 14).

De cara al ser humano, la Familia es la institución que mejor cumple con las funciones esenciales para el desarrollo de todo ser humano, a saber: la función biológica (sexual y reproductiva), educativa (socializa a los niños en cuanto a conductas, hábitos y valores), económicas (alimentación, salud, habitación, vestuario y recreación) y la función protectora (seguridad y cuidados de sus integrantes) (Lepin Molina, 2014). Es posible, entonces, que la Familia se configure en el centro de los derechos y obligaciones de sus integrantes por el conglomerado de elementos que confluyen en la misma, no deja de llamar la atención que se encuentre como contenido constitucional por la relevancia de los aprendizajes presentes y futuros que se desarrollan en la misma.

Por su puesto, que dependiendo del rol que se tenga dentro de la Familia, las obligaciones cambian, excepto en el caso del matrimonio donde hay total igualdad en las obligaciones de sus miembros ${ }^{1}$, tal como ocurre en las uniones estables y monogámicas entre personas libres de vínculo matrimonial, a tenor de los artículos 67 y 68 constitucional.

Además, la Familia tiene como responsabilidad la protección y acogida de las personas adultas mayores que sean miembros de las mismas, incluso su abandono es sancionado conforme al artículo 38 de la Constitución de la República del Ecuador (2008).

\footnotetext{
${ }^{1}$ Es menester resaltar, que las responsabilidades productivas y de acompañamiento se asumen bajo el criterio de la igualdad, en este sentido sostiene el artículo 333 de la Constitución de la República del Ecuador (2008) lo siguiente: "Se reconoce como labor productiva el trabajo no remunerado de autosustento y cuidado humano que se realiza en los hogares.

El Estado promoverá un régimen laboral que funcione en armonía con las necesidades del cuidado humano, que facilite servicios, infraestructura y horarios de trabajo adecuados; de manera especial, proveerá servicios de cuidado infantil, de atención a las personas con discapacidad y otros necesarios para que las personas trabajadoras puedan desempeñar sus actividades laborales; e impulsará la corresponsabilidad y reciprocidad de hombres y mujeres en el trabajo doméstico y en las obligaciones familiares.

La protección de la seguridad social se extenderá de manera progresiva a las personas que tengan a su cargo el trabajo familiar no remunerado en el hogar, conforme a las condiciones generales del sistema y la ley" (Resaltado nuestro).
} 
Por su parte, en lo que respecta a los miembros de la Familia que sean niños o adolescentes, la institución -Familia- debe ser un entorno de afectividad y seguridad que les permitirá satisfacer sus necesidades sociales, afectivo-emocionales y culturales, con el apoyo de políticas intersectoriales locales y nacionales, ya que los niños y adolescentes tienen derecho a la atención prioritaria privilegiando sus derechos sobre los de las demás personas, tal como lo dispone el artículo 44, ejusdem. Del mismo modo, el artículo 45 constitucional indica que los niños y adolescentes tienen derecho a una Familia y disfrutar de la convivencia familiar, y a recibir información acerca de sus progenitores o familiares ausentes, salvo que fuera perjudicial para su bienestar; por lo tanto, los responsables inmediatos de la prosecución de tales derechos son los demás miembros de la Familia.

Por otro lado, si alguno de los miembros de la Familia posee alguna discapacidad, aquella deberá procurar la equiparación de oportunidades y la integración social de los mismos.

Ahora bien, más allá de las particularidades que puedan tener los miembros de la Familia, le corresponde como responsabilidad general participar en el proceso educativo, el cual no tiene límite de edad pues como derecho acompaña a las personas durante toda su vida, según lo dispuesto en el artículo 26 constitucional.

Por lo anterior, y para poder cumplir con las responsabilidades que a cada Familia le correspondan, el Estado protegerá a las madres, padres o jefes de familia en el ejercicio de sus obligaciones, según el artículo 69 de la Constitución de la República del Ecuador (2008).

Asimismo, sostiene el Código Civil (2005) en su artículo 14, que aún en los casos de ecuatorianos residentes o domiciliados fuera del territorio del Ecuador subsisten las obligaciones que nacen de las relaciones familiares con respecto al cónyuge y parientes ecuatorianos.

Del conjunto de obligaciones mencionadas (asistencia, cuidado, protección, acompañamiento, educación, libre desenvolvimiento de la personalidad, entre otras) se genera un entramado de relaciones interconectadas que deben manejarse desde el respeto y la consideración a la institución Familia, tanto por sus miembros como por otras personas o entes 
REVISTA DE LA UNIVERSIDAD DEL ZULIA. 3época. Año 12 N³4, 2021

J. I. Calle García \& J. I. Calle Antón /// Nociones sobre la Familia y el Buen Vivir Ecuatoriano, 379-397

DOI: http://dx.doi.org/10.46925//rdluz.34.22

externos a ella ${ }^{2}$, incluso el artículo 81 constitucional determina que a través de la ley se establecerán procedimientos especiales y expeditos para juzgar y sancionar los delitos de violencia intrafamiliar (es causal de divorcio a tenor del artículo 110 , numeral $2^{\circ}$ del Código Civil), sexual, crímenes de odio y los que se cometan contra niñas, niños, adolescentes, jóvenes, personas con discapacidad, adultas mayores y personas que, por sus particularidades, requieren una mayor protección; de manera que la Familia tiene un carácter especialísimo en el ordenamiento jurídico ecuatoriano ${ }^{3}$.

De lo anterior se desprende, que las personas que se encuentran dentro de una Familia desarrollan lazos afectivos y que, si bien existen obligaciones dispuestas por el ordenamiento jurídico, no es menos cierto que los sentimientos especiales entre sus miembros tienen un peso importante en el cumplimiento de las mismas. La Familia como institución única y cambiante es el reflejo de las transformaciones a lo largo del tiempo, procura el bienestar de cada uno de sus integrantes desde lo biológico, psicológico, económico, social, razón por la cual la mayor responsabilidad de la Familia es la satisfacción de las necesidades, no sólo porque el ordenamiento jurídico lo determine sino por la fraternidad y sentimientos que unen a sus miembros.

3. Relación entre la Familia y el Buen Vivir como paradigma de vida

La sociedad contempla diferentes conductas que deben confluir en las rutinas económicas, políticas, culturales, sociales, que permitan el desarrollo del conjunto de instituciones, una de ellas es la Familia que debe actuar conforme a sus valores y principios, muchos de ellos ancestrales o heredados por los aprendizajes del entorno más cercano de una persona, pero al hacerlo debe utilizar factores o elementos que la naturaleza otorga, ya que se tiene como finalidad alcanzar la satisfacción de las necesidades o colmar derechos, en todo caso llegar al Buen Vivir. Por ello, los paradigmas o esquemas de vida deben confluir con respeto

2 "De esta forma, el Estado va intervenir, por intermedio de la justicia de familia, cada vez que resulte necesario hacerlo, es decir, en todos aquellos casos en que las partes no logran solucionar de mutuo acuerdo sus conflictos familiares, o en los casos que sea necesario actuar para proteger a los más débiles, como en supuestos de violencia intrafamiliar o vulneración de los derechos de los niños, niñas o adolescentes" (Lepin Molina, 2014: 47).

${ }^{3}$ En este orden de ideas, la Corte Constitucional de la República del Ecuador (2017: Sentencia 0001-17-HD) sostiene en este sentido, que "el hábeas data salvaguarda derechos como la honra, la buena reputación, la intimidad personal y familiar, entre otros, permitiendo al juez disponer el acceso, la eliminación y/o rectificación de la información”. 
entre los mismos; en este sentido, tanto la Familia como el Buen Vivir tienen elementos caracterizadores que les son comunes a ambas instituciones, los cuales son descritos a continuación:

a. Ancestral: tanto la Familia como el Buen Vivir devienen de tiempos remotos, son instituciones que han sido asumidas desde la existencia del ser humano, y conllevan a jerarquías o sistemas de organización que se trasladan a otros sectores como el laboral, el económico, el social. En el caso de la Familia, si bien ha pasado por cambios, no es menos cierto que la Familia tradicional se mantiene; y, en lo que respecta al Sumak Kawsay, su origen amerindio implica concepciones, igualmente, tradicionales donde se siguen ideas, costumbres o normas del pasado.

b. Connotaciones o significados varios: de las consideraciones realizadas líneas arriba se evidencia que no existen un único concepto de Familia o de Buen Vivir, puesto que en cada uno hay diversas perspectivas de lo que se entiende como fundamento, sustento o núcleo fundamental de la sociedad, o meta a alcanzar o conjunto de derechos, que en todo caso deben propender a la deferencia con la naturaleza o Pacha Mama.

c. Coinciden diferentes modos de vida y/o personas: en lo que respecta a la familia, al estar constituida por personas, cada una tiene derecho al libre desarrollo de su personalidad y a ser respetado por el resto de los miembros del conjunto; así sucede también con el Buen Vivir, en el cual deben coordinarse modos de vida amerindios y urbanos, teniendo por norte obtener beneficios para todos, en especial para la Pacha Mama. Vale señalar que el respeto requiere de protección y cuidados entre los miembros; en tal sentido señala la Corte Constitucional de la República del Ecuador (2020: Sentencia 3-19-JP/20) lo siguiente:

"El derecho al cuidado refiere a las actividades que una persona requiere para ejercer derechos y reproducir la vida, mediante la construcción y el fortalecimiento de vínculos y condiciones para realizar el sumak kawsay.

Por el derecho a cuidar una persona cuenta con el tiempo necesario y suficiente para desarrollar vínculos con otra que necesita cuidado. El derecho a cuidar es una manifestación de respeto, consideración, y empatía a otra persona o ente vivo. Por el derecho a ser cuidado, una persona requiere ser atendida en relación con una necesidad por carecer de autonomía, tener su autonomía disminuida o no contar con las condiciones para ejercer el autocuidado" 
En todo caso, tanto la Familia como el Buen Vivir requieren de pactos de convivencia por la multiplicidad de criterios y personas que a lo interno de ellos coexisten; con dichos acuerdos se reconoce la interdependencia entre los sujetos, sin dejar de lado la atención prioritaria de los niños, adolescentes, personas de la tercera edad, personas con discapacidad, o grupos de atención prioritaria.

La Constitución Política contiene reglas de organización y estructura del Estado, lo que implica la existencia de ciertos valores, principios fundamentales, derechos y garantías de las personas, ello trae aparejadas pautas claras para una convivencia pacífica y la construcción de la democracia dentro de un marco de dignidad de la persona, justicia, libertad, igualdad y pluralismo cultural (Cardoso Ruíz et. al., 2016).

Es necesario el reconocimiento de todos y de todo, es decir, admitir que la multiplicidad, que las personas y sus aspiraciones son diversas pero iguales, por lo que las sociedades deben aceptar su naturaleza pluriétnica e intercultural, y este reconocimiento debe estar garantizado en los distintos órdenes constitucionales y en la práctica cotidiana de la vida de un país (Cardoso Ruíz et. al., 2016), y ello aplica tanto para la Familia como para el Buen Vivir.

d. Elemento natural: ambas figuras tienen una vinculación plena con la naturaleza, no solo por el hecho mismo de sus orígenes, sino que en su composición y desarrollo requieren de factores que nacen de la Pacha Mama, para transformarlos y colmar necesidades. De este modo, la Corte Constitucional de la República del Ecuador (2015: Sentencia 166-15-SEP-CC), señala lo siguiente:

"Ahora bien, los derechos de la naturaleza constituyen una de las innovaciones más interesantes y relevantes de la Constitución actual, pues se aleja de la concepción tradicional "naturaleza-objeto" que considera a la naturaleza como propiedad y enfoca su protección exclusivamente a través del derecho de las personas a gozar de un ambiente natural sano, para dar paso a una noción que reconoce derechos propios a favor de la naturaleza. La novedad consiste entonces en el cambio de paradigma sobre la base del cual, la naturaleza, en tanto ser vivo, es considerada un sujeto titular de derechos".

Además, tanto la Familia como el Buen Vivir enaltecen valores naturales del ser humano como las conexiones entre ellos para lograr colmar necesidades, es inmanente a su crecimiento 
y desarrollo, ambas figuras forman parte natural, habitual, permanente de la sociedad, aunque tienen diferentes perspectivas según quien interprete o analice a la Familia o al Buen Vivir, ostentan un lugar privilegiado en la sociedad y vitales para la existencia del ser humano.

e. Contenido constitucional: el ordenamiento jurídico ecuatoriano le otorga rango constitucional a la Familia y al Sumak Kawsay elevando su jerarquía jurídica, por el alto grado de importancia que ambas figuras revisten, es decir, ambos tienen supremacía constitucional.

"El constitucionalismo representa, en la actualidad, una fuerte corriente de renovación del Derecho, evidenciándose, de esta forma, lo que suele denominarse como "Supremacía de la Constitución", en donde todos los poderes públicos, así como los particulares, nos hallamos sometidos a las normas contenidas en la Carta Fundamental" (Corte Constitucional de la República del Ecuador, 2009: Sentencia 003-09-SEP-CC).

Con la combinación constitucional de las figuras bajo comentario, se genera un camino jurídico para conseguir el reconocimiento, sostenimiento y efectivo respeto de una amplísima gama de derechos en condiciones de igualdad, incentivando el Buen Vivir para lograr alcanzarlo a través del enaltecimiento del rol de la Familia y su proyección social, evitando la fractura de ambos o de alguno de ellos, ya que son importantes figuras para lograr el desarrollo y el crecimiento económico de la mano de la naturaleza, teniendo a ésta como epicentro de las decisiones individuales y colectivas. En todo caso, el modelo sería dedicarle tiempo y esfuerzos a la Familia para alcanzar el Buen Vivir.

Estos paradigmas de vida reflejan el compromiso del Estado ecuatoriano de conectarlos para mejorar las condiciones de cada ser humano, pero desde la perspectiva de la naturaleza, es decir, no antagonizan las aspiraciones de la Familia con el Buen Vivir, sino que son varios los denominadores que en común tienen ambas figuras pues son ancestrales, con varios significados, donde confluyen diferentes modos de vida, son naturales y forman parte del contenido de la Constitución de la República del Ecuador (2008). Concertar la Familia y el Buen Vivir permite dotar a las personas de condiciones para vivir en armonía con sus semejantes y con la naturaleza, sea en el medio amerindio o urbano, pero con suficiente ahínco tradicional en las generaciones del presente, para trasladar los aprendizajes a las generaciones futuras. 
Aunado a lo anterior, el acercamiento entre la Familia y el Buen Vivir se puede extraer del artículo 319 constitucional, ya que da cuenta de la organización productiva y económica de la Familia siempre que asegure el Buen Vivir, la referida disposición establece lo siguiente:

"Artículo 319. Se reconocen diversas formas de organización de la producción en la economía, entre otras las comunitarias, cooperativas, empresariales públicas o privadas, asociativas, familiares, domésticas, autónomas y mixtas.

El Estado promoverá las formas de producción que aseguren el buen vivir de la población y desincentivará aquellas que atenten contra sus derechos o los de la naturaleza; alentará la producción que satisfaga la demanda interna y garantice una activa participación del Ecuador en el contexto internacional".

De tal manera, que la conexión entre Familia y Buen Vivir debe traer aparejado el desarrollo pues para la sobrevivencia del ser humano desde el contexto familiar-derivado de las responsabilidades correspondientes-requiere de la naturaleza, enalteciéndola como factor determinante para alcanzar el Sumak Kawsay. El binomio Familia-Buen Vivir es indispensable para lograr el desarrollo del entorno.

\section{Conclusiones}

Considerar al ser humano como aislado, no es factible, es un ser social y natural. Cada persona debe desenvolverse en Familia, pues será la primera institución que le permita conocer y aprender valores y principios; una tarea o responsabilidad que se encamina en paralelo con el respeto al entorno, tanto del resto de las personas, como, especialmente, de la naturaleza. Conjugar acciones para satisfacer necesidades y derechos es el camino para alcanzar el Buen Vivir dispuesto en el Preámbulo de la Constitución de la República del Ecuador (2008), construido desde tiempos antiguos por grupos amerindios y trasladados hasta el presente.

La Familia y el Buen Vivir son instituciones ancestrales, diversas en sus concepciones, pero que dan cuenta de distintos modos de vida y de personas, con la naturaleza de la que nacen y amparan a través de los contenidos constitucionalmente consagrados, en aras de lograr el desarrollo. 
Referencias

Asamblea Nacional Constituyente (2008). Constitución Política de la República del Ecuador. Registro Oficial número 449, de fecha 20 de octubre de 2008. Quito, Ecuador.

Asamblea General de las Naciones Unidas (1948). Declaración Universal de Derechos Humanos. París, Francia.

Cardoso-Ruiz, René Patricio; Gives-Fernández, Luz del Carmen; Lecuona-Miranda, Ma. Enriqueta; Nicolás-Gómez, Rubén (2016). Elementos para el debate e interpretación del Buen vivir/Sumak kawsay. México. En: Contribuciones desde Coatepec. Número 31. Universidad Autónoma del Estado de México. P.p. 1-24.

Congreso Nacional (2005). Código Civil. Registro Oficial Suplemento 46, de fecha 24 de junio de 2005. Última modificación de fecha 22 de mayo de 2006. Ecuador.

Corte Constitucional de la República del Ecuador (2020). SENTENCIA N. 3-19-JP/20. Acción de protección. En: https://www.corteconstitucional.gob.ec/, fecha de consulta: 05-12-2020.

Corte Constitucional de la República del Ecuador (2017). SENTENCIA N. 0001-17-HD. Hábeas Data. En: https://www.corteconstitucional.gob.ec/, fecha de consulta: 05-12-2020.

Corte Constitucional de la República del Ecuador (2015). SENTENCIA N. 166-15-SEP-CC. Acción Extraordinaria de Protección. En: https://www.corteconstitucional.gob.ec/, fecha de consulta: 05-12-2020.

Corte Constitucional de la República del Ecuador (2009). SENTENCIA N. 0 003-09-SEP-CC. Acción Extraordinaria de Protección. En: https:/www.corteconstitucional.gob.ec/, fecha de consulta: 05-12-2020.

De La Fuente Linares, José; Cándido Francisco Javier (2012). La protección constitucional de la familia en América Latina. En: IUS Revista del Instituto de Ciencias Jurídicas de Puebla, México. Número 29. México. P.p. 60-76.

Esborraz, David Fabio (2015). El concepto constitucional de familia en América Latina. Tendencias y proyecciones. En: Revista de Derecho Privado. Número 29. Universidad Externado de Colombia. Bogotá, Colombia. P.p. 15-55.

Galiano-Maritan, G.; Tamayo-Santana, G. (2018). Análisis constitucional de los derechos personalísimos y su relación con los derechos del buen vivir en la Constitución de Ecuador. En: Revista de Derecho Privado. Número 34. P.p. 123-156. DOI: https://doi.org/10.18601/01234366.n34.05.

Lepin Molina, Cristián (2014). Los Nuevos Principios del Derecho de Familia. En: Revista Chilena de Derecho Privado. Número 23. P.p. 9-55. 
Morocho Ajila, Segundo (2017). Sumak Kawsay: ¿estrategia política o filosofía de vida? En: Universitas, Revista de Ciencias Sociales y Humanas de la Universidad Politécnica Salesiana del Ecuador. Año XV. Número 26. P.p. 179-198.

Oliva Gómez, Eduardo; Villa Guardiola, Vera Judith (2013). Hacia un concepto interdisciplinario de la familia en la globalización. En: Justicia Juris. Volumen. 10. Número 1. P.p. $11-20$.

Ortiz, Pablo (2009). Sumak kawsay en la Constitución ecuatoriana de 2008: apuntes en torno a sus alcences y desafíos. ALTERIDAD. En: Revista de Educación. Volumen 4. Número 1. Universidad Politécnica Salesiana. Cuenca, Ecuador. P.p. 76-87.

Pérez-Morón, Laura Yesica; Cardoso-Ruiz, René Patricio (2014). Construcción del Buen Vivir o Sumak Kawsay en Ecuador: una alternativa al paradigma de desarrollo occidental. Toluca, México. En: Contribuciones desde Coatepec. Número 26. Universidad Autónoma del Estado de México. Pp. 49-66

Ribadeneira Aroca, Kepler (2020). Buen Vivir: críticas y balances de un paradigma social en construcción. En: Diálogo Andino. Número 62. Universidad Técnica de Manabí. Facultad de Humanística y Ciencias Sociales. Portoviejo. Manabí, Ecuador. P.p. 41-5l.

Salgar Cubillos, César Augusto (2017). Concepto de familia: cambios estructurales y conceptuales desde la interdisciplinariedad, las teorías de género y la psicología. Una revisión documentada. Trabajo de grado. Fundación Universitaria Los Libertadores. Facultad de Psicología.

En: https://repository.libertadores.edu.co/bitstream/handle/11371/125l/salgarcesar20l7.pdf?sequenc $\mathrm{e}=2 \&$ is Allowed $=\mathrm{y}$

Villabella-Armengol, Carlos Manuel (2016). Constitución y familia. Un estudio comparado. En: Díkaion. Volumen. 25. Número 1. Universidad de La Sabana. Cundinamarca, Colombia. P.p. 100131 . 